\title{
LDB e ampliação da jornada Uma abordagem do ciclo de políticas
}

\author{
Geovana Mendonça Lunardi Mendes* \\ VÂNio Cesar SEEMANN**
}

\begin{abstract}
RESUMO: Este artigo visa problematizar a política de ampliação da jornada escolar no ensino fundamental brasileiro, conforme estabelece o Art. 34 da Lei de Diretrizes e Bases da Educação (LDB). O estudo fundamenta-se nos estudos sobre a política educacional tendo como método de análise o ciclo de políticas proposto por Stephen J. Ball e seus colaboradores (1992, 1994).
\end{abstract}

Palavras-chave: Jornada integral. Ciclo de políticas. Política educacional. LDB.

\section{The legal guidelines and bases for education (LDB) and the increased working day A policy cycle approach}

\begin{abstract}
This article seeks to look at the problems with the policy of expansion in the school day in the Brazilian basic education system, as was established through Art. 34 of the legal guidelines and bases for education (LDB). This work is based on other studies on educational policy and takes as an analytical model the
\end{abstract}

* Doutora em Educação. Pós-doutora em Educação. Professora Associada do quadro permanente da Universidade do Estado de Santa Catarina (Udesc), atuando no Centro de Ciências Humanas e da Educação (FAED) no curso de Pedagogia e no Programa de Pós-graduação em Educação (PPGE) - Mestrado e Doutorado. Também é Vice Presidente da ANPED Nacional, representando a região sul e Líder do Grupo de Pesquisa do CNPq “Observatório de Práticas Escolares” e coordenadora do Observatório da Educação: Tablets, Computadores e Laptops, e do Observatório em Rede "Escolarização de Sujeitos com Deficiência Intelectual" em parceria com a UNIVALI e UFRRJ, aprovado no Edital OBEDUC/ CAPES. Florianópolis/ SC - Brasil. E-mail: <geolunardi@gmail.com>.

* Mestrando em Educação. É Orientador Educacional de carreira na Secretaria Municipal de Educação (SME) de Florianópolis, onde ocupou diversos cargos de Direção e Gerência. É formador de docentes no programa de Formação Continuada da Secretaria Municipal de Educação, nas modalidades presencial e à distância e coordena programas e projetos institucionais de educação integral e educação das relações étnico-raciais. Florianópolis/SC - Brasil. E-mail: < vanio1971@yahoo.com.br>. 
policy cycle approach proposed by Stephen J. Bell and his collaborators $(1992,1994)$.

Key words: Full-time working day. Policy cycles. Educational policy. Legal guidelines and bases for education (LDB).

\section{LDB y ampliación de la jornada}

Una aproximación desde el ciclo de políticas

RESUMEN: Este artículo tiene el objetivo de analizar la política de ampliación de la jornada escolar en la enseñanza fundamental brasileña, como establece el Art. 34 de la Ley de Directrices y Bases de la Educación (LDB). El estudio se basa en los estudios sobre la política educativa y en el método de análisis del ciclo de políticas propuesto por Stephen J. Ball y sus colaboradores $(1992,1994)$.

Palabras clave: Tiempo completo. Ciclo de políticas. Política educativa LDB.

\section{LDB et augmentation du temps scolaire}

Une approche du cycle de politiques

RÉSUMÉ: Cet article a pour objectif de problématiser l'augmentation du temps de la journée scolaire au sein de l'enseignement fondamental brésilien, conformément à l'Art. 34 de la Loi des Lignes Directrices et de Bases de l'Education (LDB). L'étude se fonde sur la politique éducationnelle avec pour méthode d'analyse le cycle de politiques proposé par Stephen J. Ball et ses collaborateurs $(1992,1994)$.

Mots-clés: Journée intégrale. Cycle de politiques. Politique éducationnelle. LDB. 


\section{Introdução}

Lei de Diretrizes e Bases da Educação (LDB), instituída pela Lei no 9.394, de
20 de dezembro de 1996, é um dos mais relevantes textos definidores de polí-
ticas públicas educacionais no Brasil. A partir da sua promulgação, emergiu um amplo leque de outros textos políticos que vêm produzindo um novo ordenamento jurídico e institucional. Em seu escopo, a progressiva ampliação da jornada escolar no ensino fundamental é um indicativo da perspectiva de promover a formação integral dos estudantes, descortinando desafios complexos aos gestores educacionais, pesquisadores do campo da educação e os professores.

Destarte, tempo integral e educação integral são conceitos que têm perpassado a política educacional, revelando um complexo grau de polifonia e polissemia, onde perspectivas emancipadoras e assistencialistas se aninham, como apontam os estudos de Ana Maria Cavaliere (2002, 2007, 2009). As pesquisas acadêmicas em torno da questão da educação integral e da jornada integral têm crescido significativamente ao longo do tempo, como apontam os estudos de Anelice Ribetto e Lúcia Velloso Maurício (2009), Larissa Katsumata Gusmão e Adolfo Ignacio Calderón (2014) e Cris Regina Gambeta Junckes (2015).

Tencionamos problematizar a política de ampliação da jornada escolar no ensino fundamental brasileiro e suscitar reflexões, que permitam uma compreensão mais apurada sobre os contextos que lhe são atinentes e à reforma educacional que se encontra em curso, utilizando-nos da abordagem do ciclo de políticas.

\section{O método de pesquisa: definindo as lentes de análise}

O ciclo de políticas proposto por Richard Bowe, Stephen J. Ball e Anne Gold (1992) busca estabelecer um conjunto conceitual dinâmico e flexível que possibilite o estudo das políticas. Sob esta lente, refuta-se a ideia de que as políticas são simplesmente implementadas, partindo do reconhecimento de que as políticas são contextualizadas, recontextualizadas, contestadas, traduzidas e transformadas pelos atores envolvidos.

Tomando a política como um ciclo que se constitui num continuum, a abordagem do ciclo de políticas propõe a análise de três contextos: o contexto de influência, o contexto da produção de texto, o contexto da prática. Cada contexto revela arenas, lugares, tempos e grupos de interesse, onde se estabelecem disputas e embates (MAINARDES; FERREIRA; TELLO, 2011). Como argumenta Stephen J. Ball, em entrevista a Mainardes e Marcondes (2009):

Os contextos podem ser pensados de outra maneira e podem ser 'aninhados' uns dentro dos outros. Assim, dentro do contexto de prática, você poderia ter um 
contexto de influência e um contexto de produção de texto, de tal forma que o contexto de influência dentro do contexto da prática estaria em relação à versão privilegiada das políticas ou da versão privilegiada da atuação. Assim, podem existir disputas ou versões em competição dentro do contexto da prática, em diferentes interpretações de interpretações. E, ainda, pode haver um contexto de produção de texto dentro do contexto de prática, na medida em que materiais práticos são produzidos para utilização dentro da atuação. (p. 306-307).

O contexto de influência é entendido como o ponto inicial, ou seja, a elaboração das políticas públicas, com seus respectivos movimentos, tensões e embates, que engendram a criação da política. Desse modo, o contexto de influência se configura como o território onde se criam os discursos, terminologias e conceitos, que pretendem legitimar uma determinada intervenção, logo, onde se produzem os princípios balizadores da política, decorrentes de tensionamentos e disputas de poder entre múltiplos atores pela hegemonia de seus interesses. Interesses estes que, comumente, são antagônicos.

São os princípios estabelecidos no contexto de influência, de natureza marcadamente macropolítica, que serão recontextualizados para outros contextos. Pela dinamicidade do processo, é importante dizer que as políticas não são somente constituídas nesse contexto, já que os demais contextos acabam gerando tensões sobre ele e, com isso, reconfigurando as influências.

O contexto da produção de texto consubstancia o texto político, ou seja, onde se apresentam as narrativas do discurso, que se configuram como a representação, a expressão da política, ou seja, articulados com a linguagem do interesse público geral. Os textos políticos são, nessa tessitura, resultantes de lutas, negociações e alianças entre diferentes esferas (LOPES; MACEDO, 2011).

Para Ball (1994), os textos produzidos resultam numa bricolage', que é fruto de contradições e antagonismos, culminando em incoerências e contradições, que devem ser compreendidas como resultado das "hibridizações" típicas do jogo político, razão pela qual apresentam características mais genéricas. Geralmente, são pouco claros e carregam consigo uma projeção idealizada de mundo. É elucidativo o que afirmam Shiroma, Campos e Garcia (2005, p. 432):

Por isso, textos devem ser lidos com e contra outros, ou seja, compreendidos em sua articulação ou confronto com outros textos. Tal movimento, que fecunda o campo da educação com discursos produzidos em outros campos discursivos, demarca um novo terreno de análise - a intertextualidade como uma dimensão constituinte dos textos de reforma.

Como vemos, para as autoras, a intertextualidade ${ }^{2}$ está relacionada com o processo de produção dos textos e sua historicidade, os quais são possíveis de ser captados e compreendidos por meio de uma dupla relação - "dos textos na história e da história nos textos" (SHIROMA; CAMPOS; GARCIA, 2005, p. 432). Ou seja, a intertextualidade 
indica como os textos podem transformar discursos anteriores e reestruturar as convenções existentes, revelando, assim, os processos intertextuais como processos de luta pela hegemonia do discurso e que, por sua vez, são afetados também por essa luta.

Em que pese os mecanismos discursivos pelos quais o(s) autor(es) do texto político busque $(\mathrm{m})$ controlar os sentidos, o controle é frágil: pela lógica da política que lhe é imanente ou pelas próprias características que são inerentes a um texto (LOPES; MACEDO, 2011). Os discursos utilizam-se das palavras e seus significados para construir possibilidades de pensamento. A ordenação e a combinação das palavras privilegiadas num discurso deslocam e excluem outras ordenações e combinações, deixando, explícita ou tacitamente, se revelarem poderes e desejos. Os discursos validam determinadas formas e práticas de organização - tanto quanto concepções de mundo, de ser humano e de educação - em detrimento de outras. Dessa maneira, possibilidades são oferecidas e outras eliminadas num cenário onde os atores são construídos e posicionados de formas diferentes, dentro dos distintos discursos, e, também, distribuindo o poder e o conhecimento.

Com base no aludido, o texto político pode ser lido e compreendido considerando-se o jogo político em que foi construído e em articulação e relação com outros textos políticos, que circulam. Ademais, os textos políticos têm uma historicidade representacional que adentra espaços institucionais e sociais, que não são uma tábula rasa e, por conseguinte, são recriados a cada leitura no contexto da prática, que assume uma dimensão produtiva, muito embora isso não possa ser compreendido distante da coerção e dos constrangimentos produzidos pelas relações de poder, estruturadas e distribuídas pela política.

O contexto da prática constitui o processo de tradução ou transformação do texto político, na prática. Esse contexto é também marcado por disputas onde contestações, significações e ressignificações se processam, envolvendo múltiplos atores e interesses, através de empréstimos, adaptações e apropriações, realizadas por meio de redes. A tradução das políticas se dá por meio de leituras e releituras ativas, apresentações e reapresentações, contextualizações e recontextualizações, ordenamento e reordenamento de práticas, onde se aninham aceitação e resistência, colaboração e negociação.

Adensando a discussão, Stephen J. Ball, em entrevista a Mainardes e Marcondes (2009), ressalta:

[...] a pessoa que põe em prática as políticas tem que converter/transformar essas duas modalidades, entre a modalidade da palavra escrita e a da ação, e isto é algo difícil e desafiador de se fazer. E o que isto envolve é um processo de atuação, a efetivação da política na prática e através da prática. É quase como uma peça teatral. Temos as palavras do texto da peça, mas a realidade da peça apenas toma vida quando alguém as representa. E este é um processo de interpretação e criatividade e as políticas são assim. A prática é composta de muito mais do que a soma de uma gama de políticas e é tipicamente investida de valores locais e pessoais e, como tal, envolve a resolução de, ou luta com, expectativas e requisitos contraditórios - acordos e ajustes secundários fazem-se necessários. (p. 305). 
É oportuno destacar que a noção de representação perpassa a trajetória do contexto de influências para os contextos de produção do texto da política e da prática. Nessa perspectiva, os textos políticos são reconhecidos como representação da política e, como tal, suscetíveis de serem lidos e interpretados de formas diferentes, na prática, considerando as necessidades e expectativas que lhes são atinentes. O contexto da prática é o território ou a arena para a qual a política está endereçada e onde são experienciadas suas consequências e efeitos reais.

Em síntese, a abordagem do ciclo de políticas explicita a ideia de que as políticas, ou melhor, os textos políticos são textos de ação, que são traduzidos e experienciados no contexto da prática e estão determinados por relações de poder, que não são fixas ou imutáveis. Aninham em seu escopo incoerências e incongruências, típicas do jogo político onde foram produzidos, em contextos marcados por antagonismos e que se integram a outros textos políticos existentes e circulantes. Como tais, definem resultados específicos e delimitam as opções possíveis para decidir sobre o que fazer, mas que passam por complexos processos de (re)interpretação, de (re)significação e de tradução, numa arena marcada por disputas e tensões, que envolvem processos de aceitação e resistência.

\section{Ampliação da jornada escolar no ensino fundamental: entre textos e práticas}

Referente à jornada escolar diária no ensino fundamental, considerado uma etapa obrigatória da educação básica que tem como objetivo central a formação básica do cidadão, assim a LDB expressa:

Art. 34. A jornada escolar no ensino fundamental incluirá pelo menos quatro horas de trabalho efetivo em sala de aula, sendo progressivamente ampliado o período de permanência na escola. (BRASIL, 1996).

Como vemos, na organização da jornada escolar no ensino fundamental deverá ser estabelecido um mínimo de quatro horas diárias, sendo que a sua ampliação progressiva é um indicativo, na perspectiva da jornada escolar em tempo integral.

Foi nessa direção que a Lei no 10.172, de 9 de janeiro de 2001, aprovou o Plano Nacional de Educação para o decênio de 2001-2010 e estabeleceu no âmbito do ensino fundamental as metas 21 e 22, ou seja, ampliar progressivamente a jornada escolar e atender preferencialmente as crianças oriundas de famílias de baixa renda. Assim, na organização dos tempos e espaços educativos é indicada a necessidade de promover o apoio pedagógico e desenvolver atividades relacionadas aos esportes e às artes, portanto, em caráter de complementariedade, além de se oferecer no mínimo duas refeições diárias para os estudantes. 
É a partir dessas metas que tem origem o Decreto Federal no ${ }^{0.094}$, de 24 de abril de 2007 (BRASIL, 2007a), que instituiu o Plano de Metas Compromisso Todos pela Educação, e a Portaria Normativa Interministerial nº 17, de 24 de abril de 2007 (BRASIL, 2007b), que instituiu o Programa Mais Educação,. São textos políticos, que alavancaram ações de expansão da jornada escolar no ensino fundamental nas redes municipais e estaduais públicas de ensino. Ademais, soma-se a esses textos políticos, a Lei no 11.494, de 20 de junho de 2007 (BRASIL, 2007c), que instituiu o Fundo de Manutenção e Desenvolvimento da Educação Básica e de Valorização dos Profissionais da Educação (Fundeb)³, estabelecendo os critérios de financiamento para a jornada integral.

É oportuno destacar que nos contextos de influência e de produção desses textos políticos, o Movimento Todos pela Educação ${ }^{4}$ assumiu lugar de relevo, recompondo a agenda empresarial para o campo da educação e instituindo uma nova sensibilidade e consciência com relação ao direito à educação, sobretudo, no que concerne à formação de um cidadão adequado aos interesses e valores hegemônicos e à adoção do gerencialismo e da performatividade, como tecnologias basilares na gestão da educação pública (SHIROMA; CAMPOS; GARCIA, 2011).

Atinente à ampliação da jornada escolar, a Resolução CNE/CEB nº 4, de 13 de julho de 2010, que define as Diretrizes Curriculares Nacionais Gerais para a Educação Básica, reforçou a definição da jornada integral como o tempo escolar de, no mínimo, sete horas diárias, reafirmando a ideia de que o seu desenvolvimento pode se realizar exclusivamente no espaço escolar, como também em outros espaços educativos, apontando para a necessidade de se desenvolver um currículo orgânico, sequencial e articulado, afinado com os princípios e finalidades da educação nacional e resguardado as peculiaridades regionais dos sistemas educacionais. Ademais, prevê a possibilidade da jornada integral ser oferecida em regime de turno único ou regime de turno e contraturno.

Assim, no conjunto dos textos políticos, os estudantes e a aprendizagem foram considerados a centralidade no processo de escolarização, pautando-se numa "pedagogia de competências", alinhada às prescrições de organismos internacionais multilaterais, para o que é indicado como imperativos: a reorganização dos tempos e espaços educativos; a definição dos conceitos e conteúdos a serem privilegiados, considerando a pluralidade e a diversidade cultural; a integração entre os diferentes atores da comunidade - incluindo-se aí os agentes comunitários e monitores; a formação e valorização dos profissionais da educação; e as parcerias entre os diferentes setores.

No que se refere às parcerias, é possível perceber a admissibilidade da celebração de parcerias entre os diferentes setores públicos (intersetorialidade), tanto quanto entre o setor público e o setor privado, o que tem se revelado uma tendência pesada no Brasil e na América Latina em nossa contemporaneidade, como aponta o estudo de Theresa Maria de Freitas Adrião e Teise de Oliveira Garanha Garcia (2014). Isso tem se tornado possível pela entrada de novos atores no campo da educação, bem como pelo uso de 
espaços privados para se desenvolver atividades voltadas à ampliação da jornada escolar dos estudantes. A partir desse ordenamento legal e institucional, a Lei nº 13.005, de 25 de junho de 2014, que aprovou o Plano Nacional de Educação - PNE (2014-2024), estabeleceu uma meta específica com seis estratégias para a ampliação da jornada escolar no ensino fundamental, ou seja: "Meta 6: oferecer educação em tempo integral em, no mínimo, 50\% (cinquenta por cento) das escolas públicas, de forma a atender, pelo menos, 25\% (vinte e cinco por cento) dos (as) alunos (as) da educação básica." (BRASIL, 2014).

Como vemos, a referida meta explicita o seu caráter não universalizador, na medida em que o texto legal admite que $50 \%$ das escolas brasileiras fiquem de fora da iniciativa. Se avançarmos para a questão dos estudantes a serem atendidos, a situação é visivelmente mais problemática, pois admite que $75 \%$ dos estudantes não sejam atendidos em tempo integral, numa jornada mínima de sete horas diárias. Nesse caso, a exemplo do PNE (2000-2010) anterior, a prioridade para a cobertura dos estudantes na jornada ampliada está dirigida para aqueles mais pobres ou vulneráveis socialmente.

A nosso ver, o acesso a uma escola de tempo integral com qualidade social não fica assegurado a todos os estudantes brasileiros, o que pode contribuir para proliferar desigualdades educacionais e sociais. Não resta dúvida de que a concepção de dispositivos que possibilitem a inclusão social e escolar, sobretudo para os mais pobres e vulneráveis socialmente, é importante para a promoção da justiça social. Entretanto, é possível inferir que a prescrição política e seus efeitos, no contexto da prática, estão muito mais comprometidos com o combate às tensões, violências e incivilidades, que assolam o sistema econômico de desenvolvimento em curso, do que promover uma educação de qualidade social. É emblemática, nesse caso, a admissibilidade de que qualquer ator social está apto a ensinar no interior da escola ou fora dela, como vemos na situação dos voluntários/oficineiros que atuam através do Programa Mais Educação, sem formação inicial sólida e sem remuneração. Além disso, como as condições de infraestrutura e os recursos humanos das escolas não foram devidamente alterados em favor da ampliação da jornada escolar, essa ampliação, comumente, vem se desenvolvendo de forma relativamente precarizada.

Nessa esteira, vemos que a igualdade do direito de acesso à escola de tempo integral continua comprometida, uma vez que não só se perpetuam as desigualdades escolares, mas também as desigualdades sociais, na medida em que a escola, concebida dessa maneira, acaba legitimando as desigualdades e mantendo incólumes suas reais causas, isto é, a forma de organização social, político, econômica e cultural do capitalismo, lançando mão do pretenso discurso da igualdade e da meritocracia como princípios base da justiça social num mundo marcadamente injusto.

Assim, podemos inferir que a política desenhada, no contexto da prática, tem revelado um caráter compensatório, e que acaba por segregar e impedir tal oportunidade à totalidade dos estudantes matriculados na rede pública do ensino fundamental. 
Embora a ampliação da jornada escolar esteja ancorada no compromisso com o desenvolvimento da educação integral, nas entrelinhas dos textos políticos observamos a perpetuação da lógica de hipervalorização de determinadas disciplinas, como português e matemática, dando um sentido marginal ou vulgarizado às demais áreas do conhecimento escolar na formação dos estudantes. E o que observamos é o caráter utilitário e instrumental em que se assenta a proposição da ampliação da jornada, com forte apelo à melhoria dos indicadores de rendimento, como é caso do Índice de Desenvolvimento da Educação Básica (Ideb) e o Programa Internacional de Avaliação de Estudantes (Pisa).

Face ao exposto, em que pese as narrativas dos textos políticos mencionados afirmarem o dever do Estado em promover a educação integral para os seus cidadãos - pela construção de convergências e corresponsabilidades entre Estado, profissionais da educação, comunidades, empresários, entre outros atores - no contexto da prática, essas narrativas têm produzido a "dispersão" e a fragmentação do significado de identidade, tanto no que se refere à soberania do Estado quanto à autonomia do ser humano. Nesse sentido, pondera Cinara Martins Farina Allemand (2014, p. 49):

A 'dispersão', como estratégia política para viabilizar a reestruturação do Estado, está na base dos princípios do gerencialismo. A liberação dos controles do governo abre aspectos abre o espectro necessário à procura de estratégias mais adaptativas e flexíveis, sintonizadas com as oscilações convenientes ao sistema vigente. Entretanto, essa liberação não acarreta maior liberdade às instituições educacionais, pois os mecanismos de controle centralizados se intensificam tanto objetiva quanto subjetivamente - só que por linhas bem mais indiretas e difusas e responsabilização e regulação.

Como vemos, essa estratégia contribui decisivamente para atender aos interesses do mercado, pois, ao debilitar ou desconstruir os sentidos que davam significação e pertencimento às instituições, aos estudantes e aos profissionais da educação, acaba fortalecendo o interesse das elites hegemônicas.

A análise dos textos políticos aponta para a necessidade de se pensar alternativas de uso de espaços públicos, como museus, cinemas, teatros, parques e outros ambientes, potencializadores do desenvolvimento das múltiplas dimensões dos estudantes. A proposição parece salutar numa perspectiva cidadã se considerarmos que esses são espaços de direito, possuem recursos favoráveis para a produção de sentido e significados sobre a vida, precisam ser conhecidos, vivenciados e apropriados, como condição sine qua non para uma vida digna e libertadora. Contudo, algumas questões devem ser suscitadas: quantos municípios brasileiros possuem museus, cinemas e bibliotecas? O acesso a esses espaços artísticos e culturais são gratuitos? Quantos municípios possuem centros comunitários ou praças capazes de mobilizar atividades educativas? Qual é a segurança e adequação desses espaços para o uso pedagógico dos estudantes e professores? Como deslocar os estudantes para esses espaços, sobretudo em grandes 
municípios, ou os estudantes que vivem e estudam nas zonas rurais? Estas e outras questões nos revelam muitas mazelas e precariedades no que se refere ao acesso ao usufruto desses espaços como possibilidade de ampliação da jornada escolar e da formação integral dos estudantes.

Nesse caso, pensamos que estratégias dessa natureza parecem não alterar o status quo da escola e da sociedade, senão evocar uma retórica que acaba por responsabilizar as escolas e os professores em buscar parcerias, geri-las e, quando não possível, culpabilizá-los pela não execução.

Em que pese o indicativo de que aos professores seja oportunizada a possibilidade de exercer seu ofício numa única escola - o que seria importante do ponto de vista do bem-estar, da qualidade social do trabalho e da valorização do magistério -, no contexto da prática, o que podemos inferir é que isso se faz letra morta, sobretudo porque as experiências de ampliação da jornada escolar têm sido desenvolvidas, comumente, por volunários/oficineiros, gerando mais problemas no interior das escolas, como a perda de espaços voltados ao ensino, para beneficiar o desenvolvimento das oficinas, ou por meio de profissionais contratados pelas próprias organizações não governamentais a partir do repasse de recursos financeiros públicos destinados a esse fim. Assim, o que vemos emergir é a dicotomia entre o turno e o contraturno escolar, a desarticulação entre as atividades desenvolvidas pelos professores e as atividades desenvolvidas pelos voluntários/oficineiros e o deslocamento dos diretores escolares e coordenações pedagógicas para a administração dos recursos financeiros e humanos voltados à ampliação da jornada escolar, deixando, assim, a gestão pedagógica das práticas curriculares numa condição marginal e frágil.

Ademais, ao serem (im)postas às escolas novas atribuições, para além da tarefa de educar, como gerir a celebração das parcerias públicas - em especial, com os setores da assistência social e da saúde -, bem como das parcerias público-privadas com empresas e organizações não governamentais, verifica-se que a dimensão educacional é confundida com a dimensão assistencial e uma clara abertura do atendimento público educacional para a iniciativa privada. Isso tem contribuído para fragilizar a identidade profissional dos professores, colocando em xeque, em muitos casos, o papel social e político da escola na sociedade, como argumenta Emilio Tenti Fanfani (2015). Dito isso, a ampliação da jornada escolar no ensino fundamental, nos atuais contornos, tem alcançado como efeitos, no contexto da prática, muito mais a descompressão de algumas tensões e a contenção das violências e incivilidade, numa espécie de custódia dos estudantes, como argumenta Karine de Souza Leandro (2014), do que propriamente o compromisso com a formação integral dos estudantes e a sua correspondente emancipação.

Assim, pensamos que, para desenvolver uma proposta de educação integral e sua consequente ampliação da jornada escolar, não basta a produção de materiais didáticos para serem replicados pelos professores nas suas atividades curriculares, tampouco 
desenvolver processos de formação inicial e continuada com esse fim. Pelo contrário, empoderar os professores como sujeitos críticos e pesquisadores da sua práxis educativa é um desafio que tem se revelado urgente e necessário, se pretendemos fortalecer a escola como espaço de formação humana para uma vida democrática, justa e digna.

Diferentemente das soluções milagrosas que empresas educacionais e consultorias especializadas tendem a oferecer/vender, num novo cenário marcado pela "governança" na educação e sob a lógica do mercado no interior do Estado, é revelador considerar o papel intelectual dos professores no desenvolvimento das práticas curriculares comprometidas com a qualidade social da educação escolar.

\section{Considerações finais}

Neste artigo, apresentamos algumas questões importantes em torno da ampliação da jornada escolar no ensino fundamental, conforme previsto na LDB (BRASIL, 1996), utilizando-nos da abordagem do ciclo de políticas. Para tanto, buscamos promover o diálogo entre os principais textos políticos atinentes à temática, no esforço de capturar uma compreensão mais apurada das prescrições estabelecidas e as concepções e ideias que lhe são atinentes e seus efeitos no contexto da prática.

Reconhecemos que a educação integral tem sido um ideal perseguido desde a Grécia da Antiguidade até os nossos dias, quando a ampliação da jornada escolar se revela uma necessidade, o que pressupõe a reorganização dos tempos e espaços educativos e a ampliação dos repertórios culturais dos estudantes. Contudo, a análise dos textos políticos e seus efeitos na prática nos faz ver o seu caráter não universalizador e compensatório, restrito a um universo diminuto de estudantes, com vistas à contenção das incivilidades, violências e da pobreza. Está muito mais voltada à melhoria dos indicadores educacionais do que propriamente à formação integral dos estudantes, revelando uma visão gerencialista e performativa no campo da educação escolar.

Ademais, confundindo a dimensão educacional com a dimensão assistencial, tem se revelado um campo aberto para a atuação da iniciativa privada, que passou a absorver recursos financeiros públicos destinados à área da educação, que poderiam ser potencializados na melhoria da qualidade social das condições materiais e profissionais da escola e, por decorrência, na melhoria da qualidade social da escolarização na sociedade brasileira.

Recebido em outubro de 2016 e aprovado em dezembro de 2016 


\section{Notas}

1 "Bricolage é a atividade de aproveitar coisas usadas, quebradas ou apropriadas para uso, em um novo arranjo ou em uma nova função. Lévi-Strauss introduziu este termo na linguagem antropológica para caracterizar a atividade mito-poética." (SHIROMA; CAMPOS; GARCIA, 2005, p. 442).

2 "Intertextualidade é basicamente a propriedade que têm os textos de serem cheios de fragmentos de outros textos, que podem ser delimitados explicitamente ou mesclados e que o texto pode assimilar, contradizer, ecoar ironicamente, e assim por diante." (SHIROMA; CAMPOS; GARCIA, 2005, p. 432).

3 Entre outros aspectos, essa lei trata da distribuição proporcional de recursos que compõem o Fundeb para os sistemas de ensino considerando as diferenças entre etapas, modalidades e tipos de estabelecimento de ensino da educação básica, onde, nesse caso, a questão da jornada escolar é um fator de ponderação para a escola de ensino fundamental de tempo parcial e de tempo integral. Ou seja, o repasse dos recursos oriundos do Fundeb será de acordo com o valor-aluno matriculado no ensino fundamental parcial (com no mínimo quatro horas diárias) - na proporção de 1,0 para os anos inicias e 1,10 para os anos finais - e no ensino fundamental integral, na proporção de 1,25 (independentemente dos anos escolares).

4 "Fundado em 2006, o Todos Pela Educação é um movimento da sociedade brasileira que tem como missão engajar o poder público e a sociedade brasileira no compromisso pela efetivação do direito das crianças e jovens a uma Educação Básica de qualidade. Apartidário e plural, congrega representantes de diferentes setores da sociedade, como gestores públicos, educadores, pais, alunos, pesquisadores, profissionais de imprensa, empresários e as pessoas ou organizações sociais que são comprometidas com a garantia do direito a uma Educação de qualidade. O objetivo do movimento é ajudar a propiciar as condições de acesso, de alfabetização e de sucesso escolar, a ampliação de recursos investidos na Educação Básica e a melhora da gestão desses recursos." (TODOS PELA EDUCAÇÃO, 2016).

\section{Referências}

ADRIÃO, Theresa Maria de Freitas; GARCIA, Teise de Oliveira Garanha. Tendências da privatização da educação na América Latina e Caribe. São Paulo: CLADE, 2014.

ALLEMAND, Cinara Martins Farina. A regulação e seus novos modelos para as políticas educacionais. In: CÓSSIO, Maria Fátima; RODRIGUEZA, Rita de Cássia (Orgs.). Novos modos de regulação das políticas educacionais no contexto da terceira via. Pelotas: UFPel, 2014. p. 32-52.

BALL, Stephen J. Education reform: a critical and post-structural approach. Buckingham: Open University Press, 1994.

BOWE, Richard; BALL, Stephen J.; GOLD, Anne. Reforming education \& changing schools: case studies in policy sociology. London: Routledge, 1992.

BRASIL. Lei Federal no 9.394, de 20 de dezembro de 1996. Estabelece as diretrizes e bases da educação nacional. Diário Oficial da União, Brasília, DF, 23 dez. 1996. 
Lei Federal nº 10.172, de 9 de janeiro de 2001. Aprova o Plano Nacional de Educação e dá outras providências (2001-2010). Diário Oficial da União, Brasília, DF, 10 jan., 2001.

Decreto Federal no 6.094, de 24 de abril de 2007. Dispõe sobre a implementação do Plano de Metas Compromisso Todos pela Educação. Diário Oficial da União, Brasília, DF, 24 abr., 2007a.

Ministério da Educação. Ministério do Desenvolvimento Social e Combate à Fome. Ministério do Esporte. Ministério da Cultura. Portaria Normativa Interministerial n⿳ำ 17, de 24 de abril de 2007. Institui o programa Mais Educação. Diário Oficial da União, Brasília, DF, 26 abr., 2007b.

Lei Federal no 11.494, de 20 de junho de 2007. Estabelece o Fundo de Manutenção e Desenvolvimento da Educação Básica e de Valorização dos Profissionais da Educação. Diário Oficial da União, Brasília, DF, 22 jun., 2007c.

Resolução CNE/CEB nº 4, de 13 de julho de 2010. Define Diretrizes Curriculares Nacionais Gerais para a Educação Básica. Diário Oficial da União, Brasília, DF, 14 jul., 2010.

Lei no 13.005, de 25 de junho de 2014. Aprova o Plano Nacional de Educação - PNE e dá outras providências. Diário Oficial da União, Brasília, DF, 26 jun. 2014.

CAVALIERE, Ana Maria. Escolas de tempo integral: uma ideia forte, uma experiência frágil. In: CAVALIERE, Ana Maria; COELHO, Ligia Marta. Educação brasileira em tempo integral. Petrópolis: Vozes, 2002. $1035,2007$.

Tempo de escola e qualidade na educação pública. Educação e Sociedade, v. 28, n. 100, p. 1015-

Escolas de tempo integral versus alunos em tempo integral. Em Aberto, v. 22, n. 80, p. 51-63, 2009.

FANFANI, Emilio Tenti. La escuela y la cuestión social. Ensayos de sociologia de la educación. 3. ed. Buenos Aires: Siglo Veintiuno Editores, 2015.

GUSMÃO, Larissa Katsumata; CALDERÓN, Adolfo Ignacio. Educação em tempo integral: mapeamento e tendências temáticas de teses e dissertações (1988-2011). Revista @mbienteeducação, v.7, n. 1, p. 58-89, 2014.

JUNCKES, Cris Regina Gambeta. Escola de tempo integral e o direito à infância: uma análise da produção acadêmica (1988-2014). 2015. Dissertação (Mestrado em Educação) - Centro de Ciências da Educação, Universidade Federal de Santa Catarina, Florianópolis, 2015.

LEANDRO, Karine de Souza. Programa educação integral: escolarização ou custódia? 2014. Dissertação (Mestrado em Educação) - Centro de Ciências da Educação, Universidade Federal de Santa Catarina, Florianópolis, 2014.

LOPES, Alice Casimiro; MACEDO, Elizabeth. Contribuições de Stephen Ball para o estudo de políticas de currículo. In: BALL, Stephen. J.; MAINARDES, Jefferson (Orgs.). Políticas Educacionais: questões e dilemas. São Paulo: Cortez, 2011. p. 249- 283.

MAINARDES, Jefferson; MARCONDES, Maria Inês. Entrevista com Stephen J. Ball: um diálogo sobre justiça social, pesquisa e política educacional. Educ. Soc., v. 30, n. 106, p. 303-318, 2009.

MAINARDES, Jefferson; FERREIRA, Márcia dos Santos; TELLO, César. Análise de políticas: fundamentos e principais debates teórico-metodológicos. In: BALL, Stephen J.; MAINARDES, Jefferson (Orgs.). Políticas educacionais. Questões e dilemas. São Paulo: Cortez, 2011. p. 143-172.

RIBETTO, Anelice; MAURÍCIO, Lúcia Velloso. Duas décadas de educação em tempo integral: dissertações, teses, artigos e capítulos de livros. Em Aberto, v. 22, p. 137-160, 2009. 
SHIROMA, Eneida Oto; CAMPOS, Roselane Fátima; GARCIA, Rosalba Maria Cardoso. Decifrar textos para compreender a política: subsídios teórico-metodológicos para análise de documentos. Perspectiva, v. 23, n. 2, p. 427-446, 2005.

Conversão das "almas" pela liturgia da palavra: uma análise do discurso do movimento Todos pela Educação. In: BALL, Stephen J.; MAINARDES, Jefferson (Orgs.). Políticas educacionais. Questões e dilemas. São Paulo: Cortez, 2011.

TODOS PELA EDUCAÇÃO. Disponível em: <http://www.todospelaeducacao.org.br/quem-somos/otpe/>. Acesso em: 5 nov. 2016. 